\title{
A EDUCAÇÃO AMBIENTAL PROMOVIDA PELA SALA VERDE CAPARAÓ E SUA RELAÇÃO COM AS MACROTENDÊNCIAS PEDAGÓGICAS
}

\author{
Arnaldo Henrique de Oliveira Carvalho ${ }^{1}$ \\ Gabriela Passalini Xavier ${ }^{2}$ \\ Vânia Ágda de Oliveira Carvalho ${ }^{3}$
}

Resumo: Norteadas pelo Projeto Político Pedagógico, as Salas Verdes são espaços não formais disseminadores de Educação Ambiental. A Sala Verde Caparaó vem, desde 2014, desenvolvendo práticas ambientais educativas. Relacionaram-se essas práticas com as macrotendências pedagógicas da Educação Ambiental analisando os relatórios anuais do período entre 2014 a 2016. Foram identificadas atividades que vão desde a realização de palestras e mostras audiovisuais, visitas técnicas e até avaliações da sustentabilidade de agroecossistemas. A maioria das ações são categorizadas como pragmáticas, embora este espaço disseminador também tenha proposto atividades de cunho conservacionista e crítica.

Palavras-chave: Educação Ambiental; Sala Verde; Tendência Pedagógica.

Abstract: Guided by the Political Pedagogical Project, the Green Rooms are non formal spaces that disseminate environmental education. The Green Caparaó Room has been developing environmental educational practices since 2014. These practices were related to the pedagogical macro trends in Environmental Education, analyzing the annual reports for the period from 2014 to 2016. Activities ranging from the realization of lectures and audiovisual shows, technical visits and even assessments of the sustainability of agroecosystems were identified. Most actions are categorized as pragmatic, although this dissemination space has also proposed conservationist and critical activities.

Keywords: Environmental Education; Green Room; Pedagogical Trend.

${ }^{1}$ Ifes - campus Ibatiba. acarvalho@ifes.edu.br http://lattes.cnpq.br/7520766983744062

2 Ifes- campus lbatiba. gp.passalini@hotmail.com. http://lattes.cnpq.br/9697518167768891

3 FAMINAS - Muriaé-MG. vaniaagdaocarvalho@gmail.com. http://lattes.cnpq.br/0769658610006569 


\section{Introdução}

A Educação Ambiental (EA) reúne, em seu vocábulo, dois campos de conhecimento, a Educação e a Questão Ambiental, ambos, agentes de transformação social. Cada um destes campos traz, consigo, tendências e perspectivas políticas e metodológicas próprias, mas que, ao mesmo tempo, estabelecem uma ligação por meio dos conceitos adotados (LOUREIRO, 2003).

As perspectivas da Educação Ambiental adentram à própria Educação, pois fazem uso das tendências pedagógicas educacionais e do ambientalismo, identificado na natureza e no ambiente (LOUREIRO, 2004a).

Como a primeira palavra que compõe o termo Educação Ambiental é Educação, convencionou-se que a mesma fosse uma tarefa das escolas (CUBA, 2010), devendo, pois, ser espaços democráticos, pautado em concepções, realizações e avaliações contínuas e constantes do seu projeto educativo, uma vez que busca atender aos estudantes em toda a sua diversidade (VEIGA, 2008).

No entanto, a garantia do direito à Educação e à difusão da Educação Ambiental é uma necessidade tão latente no contexto atual que ultrapassa os estigmas da chamada educação formal limitada a ambientes escolares. É cada vez mais frequente a busca e concretização de formas de ensino mais difusas, menos hierárquicas e burocráticas, focadas em englobar as experiências de vida e de promover a autonomia dos estudantes, conhecida como educação não formal (GADOTTI, 2005).

Os espaços não formais de educação se constituem em ferramentas valiosas para a Educação e, com frequência, vêm sendo utilizados por pesquisadores e professores para desenvolver atividades educativas e divulgação de pesquisa, visto que a diversificação dos ambientes de ensino amplia as possibilidades de aprendizagem e mudanças de perspectiva (MIRANDA et al., 2018).

É dentro dessa perspectiva, de espaços educativos não formais, que se encontra o projeto Sala Verde, uma iniciativa do Ministério do Meio Ambiente, em disponibilizar e democratizar a Educação Ambiental, criando oportunidades para desenvolver uma visão de mundo integrada ao ambiente e seus diversos aspectos (FONTAN; CARVALHO; GUIMARÃES, 2016).

Dentre as Salas Verdes institucionalizadas e atuantes no Estado do Espírito Santo encontra-se a Sala Verde Caparaó (SVC), localizada no município de Ibatiba, sediada pelo Instituto Federal do Espírito Santo, orientada à prática educativa ambiental, centrada na construção de conceitos, valores e atitudes.

A dinâmica do fazer educativo na Educação Ambiental tem sido influenciada, nas últimas décadas, pelas várias identidades assumidas pela Educação Ambiental, ou seja, a diversidade de nomenclaturas existentes influi 
na prática e nas reflexões pedagógicas desempenhadas a respeito da Educação Ambiental (LAYRARGUES; LIMA, 2014). Cada uma das novas "categorias" da Educação Ambiental expressa diferentes características, formas de pensar e agir que são frutos de tendências e práticas pedagógicas do cotidiano do educador.

A Educação Ambiental analisada como um campo social apresenta perfis coletivos e autônomos, conforme Layrargues e Lima (2014), devido a sua derivação dos campos ambientalista e educacional. Por este motivo, do ponto de vista analítico, torna-se fundamental discriminar, classificar e interpretar fenômenos ou processos que compõe a Educação Ambiental, estes que são diferentes entre si, mas que, devido a certas semelhanças ou elementos comuns, podem ser confundidos como uma totalidade homogênea.

Nesse sentido, visando produzir formas de conhecimento mais fiéis à realidade do processo observado ao longo das práticas de Educação Ambiental, justifica-se a realização de uma tarefa analítica, buscando refinar o olhar e se posicionar de forma mais crítica, a fim de direcionar os caminhos pedagógicos, éticos e político-sociais que melhor atendam aos interesses da comunidade em questão analisada, a qual se insere a Sala Verde Caparaó.

Diante da necessidade de enfatizar que a educação não é estática e muito menos restrita a ambientes formais de ensino, analisaram-se as atividades educativas provenientes da Sala Verde Caparaó, relacionando-as, criticamente, com as macrotendências pedagógicas da Educação Ambiental, numa tentativa audaciosa de aprimorar os resultados e enfrentar os obstáculos obtidos no decorrer do processo educativo (RIBEIRO; SILVA, 2015).

\section{Referencial Teórico}

\section{Macrotendências Pedagógicas da Educação Ambiental}

Nas últimas décadas ocorreu um amplo processo de institucionalização acadêmica da Educação Ambiental configurando, assim, um campo social. Todo este processo, que ocorreu nas últimas quatro décadas, é reflexo da inserção de agentes sociais de vários setores da sociedade, muitas vezes com discursos semelhantes, outras com discursos contrários, mas com um único intuito, expressar a forma como veem, entendem, compreendem e apreendem a "Questão Ambiental” (LOUREIRO; LAYRARGUES, 2013).

Entender como os discursos, práticas sociais e o próprio conhecimento se dão pelos diferentes integrantes dos grupos sociais significa, de acordo com Bourdieu (2007), entender o próprio campo social. Dessa forma, considerar as diferentes tendências da Educação Ambiental, consiste em compreender a própria Educação Ambiental.

Portanto, conhecer os processos históricos que compõe cada campo social da Educação Ambiental, segundo Lima (2011), é fundamental para entender o passado, as práticas educativas presentes e o futuro de cada 
campo social. Nesse sentido, a Educação Ambiental é classificada, dentre tantas adjetivações que refletem sua identidade, em três grupos principais: a conservadora, a pragmática e a crítica (LAYRARGUES; LIMA, 2011).

A prática de Educação Ambiental (EA) conservadora é aquela que se resume basicamente pela simplicidade da visão de mundo fragmentado (GUIMARÃES, 2004). Esta lógica evidencia a sociedade como a soma dos seus indivíduos, sem levar em consideração toda a complexidade expressa em suas relações.

A EA conservadora vê com romantismo toda a "Questão Ambiental" inspirando a necessidade de incentivar a preservação e a conservação da natureza, esta última como responsável pelo bem-estar do ser humano e das futuras gerações (SILVA; CAMPINA, 2011). Enquadra-se, esta macrotendência, em uma visão ambientalista, enquadrando-se 0 meio ambiente na matriz antropocêntrica.

Além disso, a EA conservadora foi tida como hegemônica por muito tempo, pois a mesma se caracteriza pelo foco no comportamento do indivíduo, assim como em resolutivas voltadas às ações deste mesmo indivíduo. Ou seja, segundo esta tendência, as ações individuais como fechar a torneira, reciclar seu lixo, ligadas também à pegada ecológica, seriam capazes de solucionar os problemas ambientais ocasionados pelo sistema capitalista (SOUSA; SANT'ANA JÚNIOR, 2018).

Outra macrotendência em Educação Ambiental, definida por Layrargues e Lima (2011) é a pragmática, que consiste em focar todos os esforços na ação para solucionar os problemas ambientais. A EA pragmática também se ocupa em estabelecer normas a serem seguidas, buscando alternativas mecânicas que solucionem as "Questões Ambientais" sem levar em consideração as questões sociais e culturais, considerando, somente, a sustentabilidade econômica e ecológica (SILVA; CAMPINA, 2011).

Palavras como comportamento, técnicas, soluções e desenvolvimento sustentável são o carro chefe desta tendência, abordando temáticas como educação para o consumo sustentável e desenvolvimento sustentável (LOUREIRO; LAYRARGUES, 2013), pautando-se em uma vertente gerencial, em que o meio ambiente é visto e analisado como recursos naturais disponíveis ao homem, que deve saber usufruir dos mesmos, de maneira consciente e sustentável, com foco na minimização dos possíveis danos causados, em prol da perpetuação da própria espécie humana.

A EA pragmática tem suas raízes no período pós segunda guerra mundial, por isso se baseia em uma compensação para os danos causados pelo modelo capitalista de mercado (LOUREIRO; LAYRARGUES, 2013).

Por fim, temos a macrotendência Crítica, a qual considera questões mais complexas, como a realidade social, histórica e cultural como forma de desvendar os reais motivos por trás dos embates envolvendo homem, sociedade e ambiente (SOUSA; SANT'ANA JÚNIOR, 2018).

revista brasileira educação ambiental 
A EA crítica leva em conta toda a questão política dentro da questão ambiental, além disso, questionar o modelo econômico vigente também faz parte da visão crítica, pautada em Paulo Freire e demais autores que pressupõem uma ação educativa baseada em transformação política, social e econômica da sociedade vigente (LOUREIRO; LAYRARGUES, 2013), destinando à Educação Ambiental, um viés politizador.

\section{Projeto Político Pedagógico}

O Projeto Político Pedagógico (PPP) consiste em um dos mais importantes instrumentos relacionados ao fazer pedagógico, cercado de significados e finalidades, concepções e reflexões sobre o posicionamento diante das questões ambientais e, talvez por isso, seja considerado complexo (SILVA, 2005; MEDEL, 2008).

O PPP é um documento norteador e facilitador que busca retratar a realidade do ambiente educativo e sua contextualização histórica (RIBEIRO; SILVA, 2015), sinalizando o caminho a ser percorrido, seus obstáculos e os meios pelos quais se pode prosseguir na direção apropriada (SILVA, 2005). Assim sendo, não pode ser estático, é preciso que o mesmo passe por constantes mudanças (SILVA; CARNIATTO; POLINARSKI, 2009).

Torna-se necessário que o PPP seja inovador e articulado com a realidade, permitindo assim que o trabalho pedagógico seja integrado e criativo, buscando alternativas para o fazer educativo (VEIGA, 2003).

$\mathrm{Na}$ sua construção, um aspecto muito importante a ser considerado são as temáticas a serem trabalhadas, que contemplem a inserção de temas geradores e não apenas conteúdos isolados e, assim, orientar para a discussão de questões sociais e políticas, analisando problemas relacionados à realidade dos educandos (HERNÁNDEZ; VENTURA, 1998). A organização desse documento pode conduzir na direção dos objetivos propostos de maneira ágil, fluida e eficiente (SILVA, 2005).

A elaboração e a execução do PPP, se aplica tanto a espaços formais quanto a espaços não formais de educação e se constitui como ferramenta fundamental na intervenção das atividades práticas que possam surtir efeitos no processo de transformação da realidade educativa (LIMA, 2017).

É nesta direção que se enquadra a inserção da Educação Ambiental Crítica, na elaboração do PPP de um espaço não formal de educação, tendo a mesma como um tema gerador, buscando e orientando a construção efetiva de estratégias para o enfrentamento de problemas socioambientais (LUZ, 2019).

O PPP é um importante aliado às Salas Verdes, no ensino e prática da Educação Ambiental, pois permitem que certos pontos sejam elencados de maneira clara e efetiva na educação, expressando o compromisso e as intenções dos educadores envolvidos no processo educativo (MIOTTO; GONÇALVES; DINARDI, 2018). 
Cada Sala Verde precisa desempenhar o papel em dinamizar e integrar diferentes setores e segmentos da sociedade na questão ambiental e, nesse sentido, elaborar o PPP permite alinhar as ações práticas desenvolvidas às práticas em Educação Ambiental, rumo à sustentabilidade (ALMEIDA, 2018). À medida que se insere no PPP uma visão mais reflexiva acerca das concepções ambientais da comunidade e das relações socioambientais que as circundam, permite-se a emancipação dos cidadãos, os quais são alcançados pela ação das Salas Verdes, possibilitando aos mesmos enfrentar, de maneira crítica, a situação nas quais estão envolvidos (MIOTTO; GONÇALVES; DINARDI, 2018).

\section{Percurso Metodológico}

Esse artigo é a síntese de uma pesquisa monográfica de conclusão do curso de Pós Graduação em Educação Ambiental e Sustentabilidade do Instituto Federal do Espírito Santo - campus Ibatiba (2 da segunda autora), no qual foi realizado um estudo de caso tendo como objeto a Sala Verde Caparaó (SVC). Nesse contexto, essa pesquisa apresentou a seguinte questão orientadora: Com qual macrotendência pedagógica da Educação Ambiental as atividades realizadas no âmbito da SVC estão mais relacionadas?

Nos procedimentos metodológicos foi utilizada a pesquisa qualitativa e, inicialmente, foi realizada uma análise documental por meio da consulta ao PPP da SVC e aos relatórios anuais dos anos 2014, 2015 e 2016. O que motivou esta análise foi que, após iniciadas as ações educativas da SVC, nenhuma reformulação do PPP foi concebida e, após compreender esse percurso, um novo PPP poderia ser elaborado com um viés mais crítico da EA.

Assim, analisou-se, mais especificamente, como a Educação Ambiental presente nas ações realizadas pela SVC se relaciona, nesse período, com as macrotendências pedagógicas descritas por Layrargues e Lima (2014), que as classifica da seguinte forma: macrotendência conservacionista, macrotendência pragmática e a macrotendência crítica.

Com intuito de aprofundar e engrandecer ainda mais a pesquisa, além de relacionar as ações educativas realizadas pela Sala Verde Caparaó com as macrotendências pedagógicas, foram também categorizadas conforme os respectivos eixos pedagógicos elucidados por Tristão (2011), os quais apresentam as dimensões vertical, horizontal ou em rede.

\section{Resultados e Discussão}

A Sala Verde Caparaó (SVC) iniciou suas atividades em 2013 quando foi lançada uma chamada pública pelo Ministério do Meio Ambiente (MMA) para criação de novos espaços disseminadores de Educação Ambiental, denominados Sala Verde.

A criação desse espaço tem como um de seus pressupostos a elaboração, de forma participativa, do Projeto Político Pedagógico (PPP) (SILVA, 2005). Dessa forma, um grupo de educadores do Instituto Federal do 
Espírito Santo - campus Ibatiba, reuniu-se para elaborar o primeiro PPP com o propósito de implantar esse espaço e, assim, receber a chancela do MMA.

O PPP tinha como objetivo desenvolver atividades culturais e sociais por meio da Educação Ambiental, dirigidas à realidade local e regional, ampliando, consequentemente, as ações de extensão, de ensino e de pesquisa (FONTAN; CARVALHO; GUIMARÃES, 2016).

Diversas ações foram realizadas desde então. Constata-se que, a maioria das atividades realizadas se enquadram, predominantemente, nas dimensões vertical e horizontal, e um menor número de ações transcorreu na dimensão em rede (Tabela 1 ).

Tabela 1: Categorização das atividades de Educação Ambiental desenvolvidas pela Sala Verde Caparaó entre 2014 e 2016

\begin{tabular}{ccc}
\hline \multicolumn{3}{c}{ Orientação Pedagógica } \\
\hline Vertical & Horizontal & Em rede \\
\hline $\begin{array}{c}\text { Palestras na Escola } \\
\text { Família Agrícola de } \\
\text { Brejetuba. }\end{array}$ & $\begin{array}{c}\text { Visita Técnica a Escolizadas em 2014 } \\
\text { Agrícola de Brejetuba }\end{array}$ & $\begin{array}{c}\text { Oficina de Capacitação da } \\
\text { Equipe de Trabalho }\end{array}$ \\
$\begin{array}{c}\text { Mostra de cinema na } \\
\text { semana do meio } \\
\text { ambiente }\end{array}$ & $\begin{array}{c}\text { Apresentação no 16o Seminário } \\
\text { Brasileiro sobre Homeopatia na } \\
\text { Agricultura Orgânica }\end{array}$ & $\begin{array}{c}\text { Implantação de um minhocário e } \\
\text { de uma composteira na EFA de } \\
\text { Participação na Feira } \\
\text { Verde }\end{array}$ \\
$\begin{array}{c}\text { 10 Seminário de Educação } \\
\text { Mostra na Feira }\end{array}$ & Ambiental e Agroecologia & \\
Ambiental em Muniz & & \\
Freire - ES & & \\
\hline
\end{tabular}

Atividades realizadas em 2015

\begin{tabular}{|c|c|c|}
\hline $\begin{array}{c}\text { Mostra Independente } \\
\text { de vídeos } \\
\text { Palestras }\end{array}$ & Visitas Técnicas & $\begin{array}{c}\text { Diagnóstico Socioambiental com } \\
\text { agricultores }\end{array}$ \\
\hline \multicolumn{3}{|c|}{ Atividades realizadas em 2016} \\
\hline $\begin{array}{l}\text { Apresentação de } \\
\text { trabalho }\end{array}$ & Plantio de Mudas & $\begin{array}{c}\text { Avaliação da Sustentabilidade } \\
\text { dos Agroecossistemas }\end{array}$ \\
\hline $\begin{array}{c}\text { Participação em } \\
\text { Eventos de Pesquisa e } \\
\text { Extensão }\end{array}$ & $\begin{array}{c}\text { Projeto Pipoca Orgânica na } \\
\text { Semana de Alimentos Orgânicos }\end{array}$ & Árvore dos Sonhos \\
\hline $\begin{array}{l}\text { Mostra Audiovisual } \\
\text { Circuito Tela Verde }\end{array}$ & $\begin{array}{l}\text { Visita Técnica Monitorada } \\
\text { Comemoração do Dia da Água }\end{array}$ & $\begin{array}{l}\text { Caminhada Diagnóstica pela } \\
\text { bacia hidrográfica do Rio Pardo }\end{array}$ \\
\hline $\begin{array}{l}\text { Curso de Introdução a } \\
\text { Agroecologia }\end{array}$ & $\begin{array}{l}\text { Organização do III Encontro de } \\
\text { Educadores Ambientais do Ifes }\end{array}$ & \\
\hline
\end{tabular}


As atividades da Sala Verde Caparaó iniciaram com a capacitação da equipe e a discussão das metas e ações a serem desenvolvidas. Além dessa ação, a implantação de um minhocário e de uma composteira foram as únicas ações em rede realizadas. As demais ações, no ano de 2014, foram a realização de palestras, a participação em feiras e mostras de meio ambiente, ambas categorizadas no eixo vertical, na medida em que somente transmitem informação. As ações na dimensão horizontal foram as visitas técnicas na EFA de Brejetuba e a organização e participação nos seminários (Figura 1).

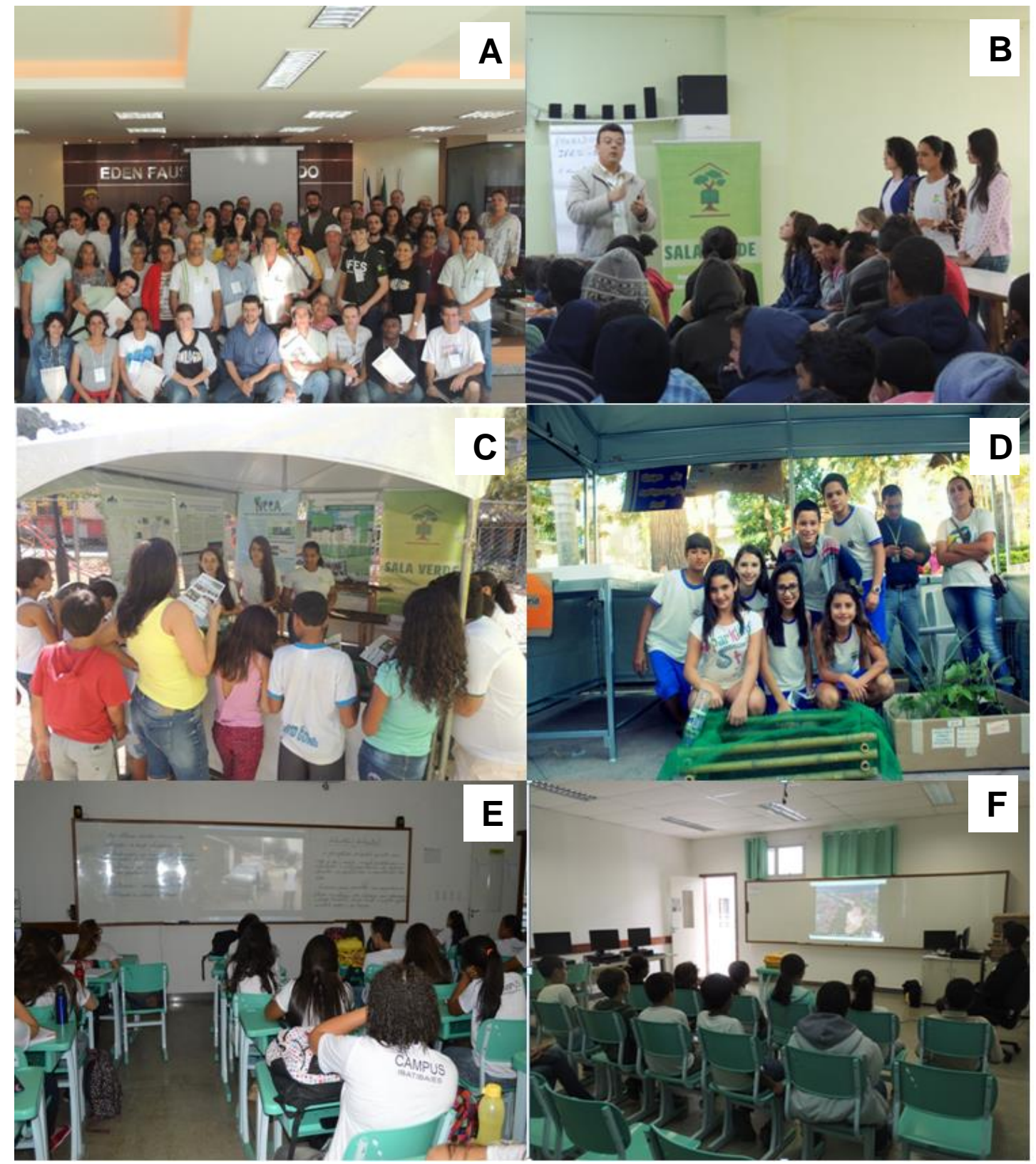

Figura 1: Primeiras ações de Educação Ambiental da SVC em 2014. A-16으 Seminário Brasileiro sobre Homeopatia na Agricultura Orgânica e 1ํ Seminário de Educação Ambiental; B-Palestra na Escola Família Agrícola de Brejetuba; C e D - Participação na Feira Verde de Ibatiba e em Muniz Freire; E e F- Mostra audiovisual. Fonte: Elaboração dos autores. 
No segundo ano do projeto (2015), assim como no primeiro, ocorreram atividades categorizadas nas três dimensões pedagógicas, porém, com menor diversidade em relação ao ano anterior. As atividades promovidas nesse ano foram a realização de palestras, as mostras audiovisuais, as visitas técnicas e os diagnósticos socioambientais com agricultores (Tabela 1).

As ações exploraram o agroecoturismo, por meio de visita ao Fjordland, em Domingos Martins/ES e ao Sítio Vovó Rosinha em Ibatiba/ES (Figura 2). Estas ações se constituíram de uma visita para conhecer pontos turísticos e as atividades de educação desenvolvidas no circuito educativo e turístico.

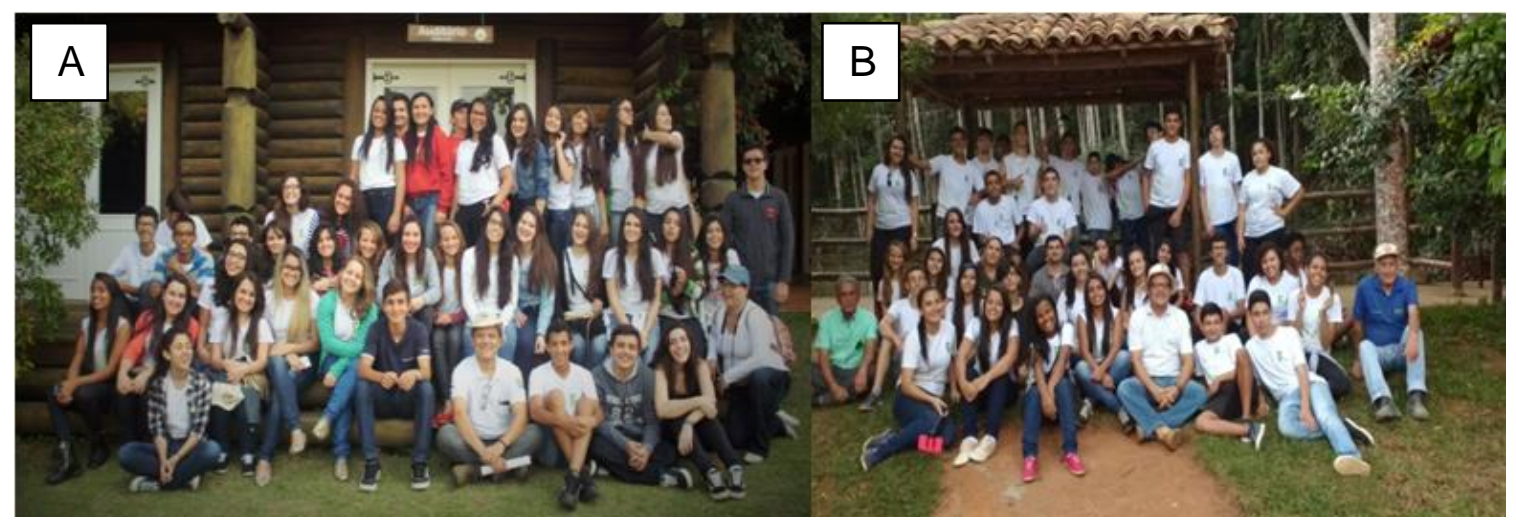

Figura 2: Visita técnica realizada em 2015 à Cavalgada Ecológica - Fjordland em Domingos Martins (A) e ao Sítio Vovó Rosinha em lbatiba (B).

Fonte: Elaboração dos autores.

Auxiliado por metodologias colaborativas, que possuem como pressuposto o diálogo e a participação e, por isso, categorizadas na dimensão pedagógica em rede (TRISTÃO, 2011), realizaram-se ações em diferentes comunidades de agricultores e agricultoras familiares de lbatiba e região, dentre elas, a Comunidade do Bairro Boa Fé em Alegre/ES, Córrego Perdido, Córrego dos Carangolas, Córrego Santa Maria e Córrego dos Rodrigues, ambos no município de Ibatiba/ES (Figura 3, próxima página).

No terceiro ano do projeto (2016), as ações desenvolvidas foram mais variadas, mesmo assim prevalecendo ações nas dimensões vertical e horizontal (Tabela 1). Parte das ações exploraram temas como Dia Mundial da Água e a Semana de Alimentos Orgânicos, sendo ambas direcionadas ao público escolar, trabalhando o amor pela natureza, ou o ser humano como destruidor da mesma, sem qualquer conotação política (Figura 4, próxima página). Estas ações permitiam maior interatividade de seus participantes, baseadas em métodos ativos, classificadas na dimensão horizontal (TRISTÃO, 2011). 


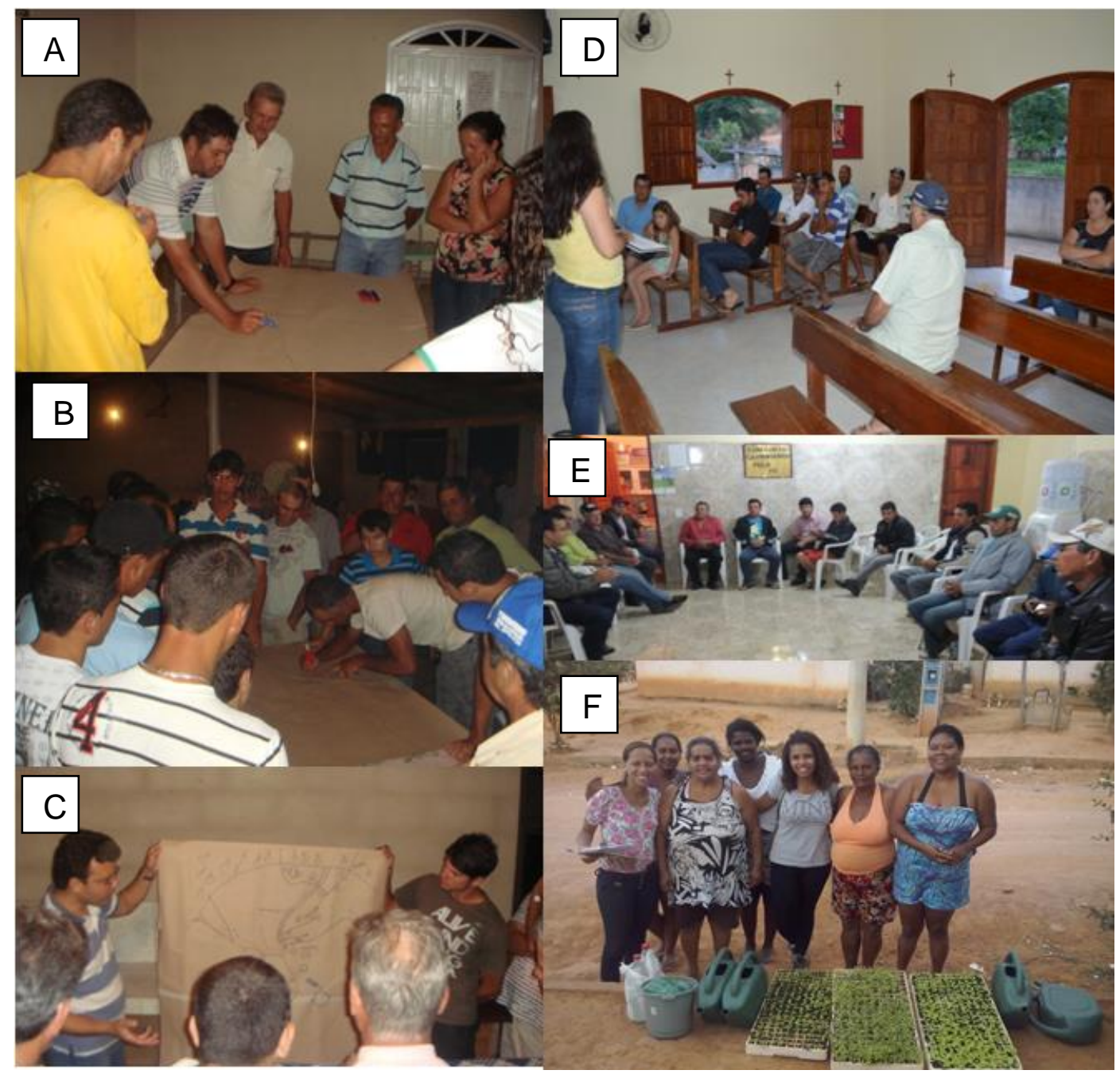

Figura 3: Ações educativas realizadas em 2015 com agricultores e agricultoras familiares nas comunidades rurais de Ibatiba. A - Córrego dos Carangolas; B - Córrego Santa Maria; C - Córregos dos Rodrigues; D e E - Córregos Perdido; F - Comunidade Boa Fé. Fonte: Elaboração dos autores.

Já as ações que possibilitaram chegar à produção de conhecimentos baseadas em métodos colaborativos, por meio da participação e do diálogo, foram os diagnósticos, tanto do agroecossistema quanto da bacia hidrográfica do Rio Pardo (Figura 5) e, por isso, categorizadas na dimensão pedagógica em rede (TRISTÃO, 2011). 


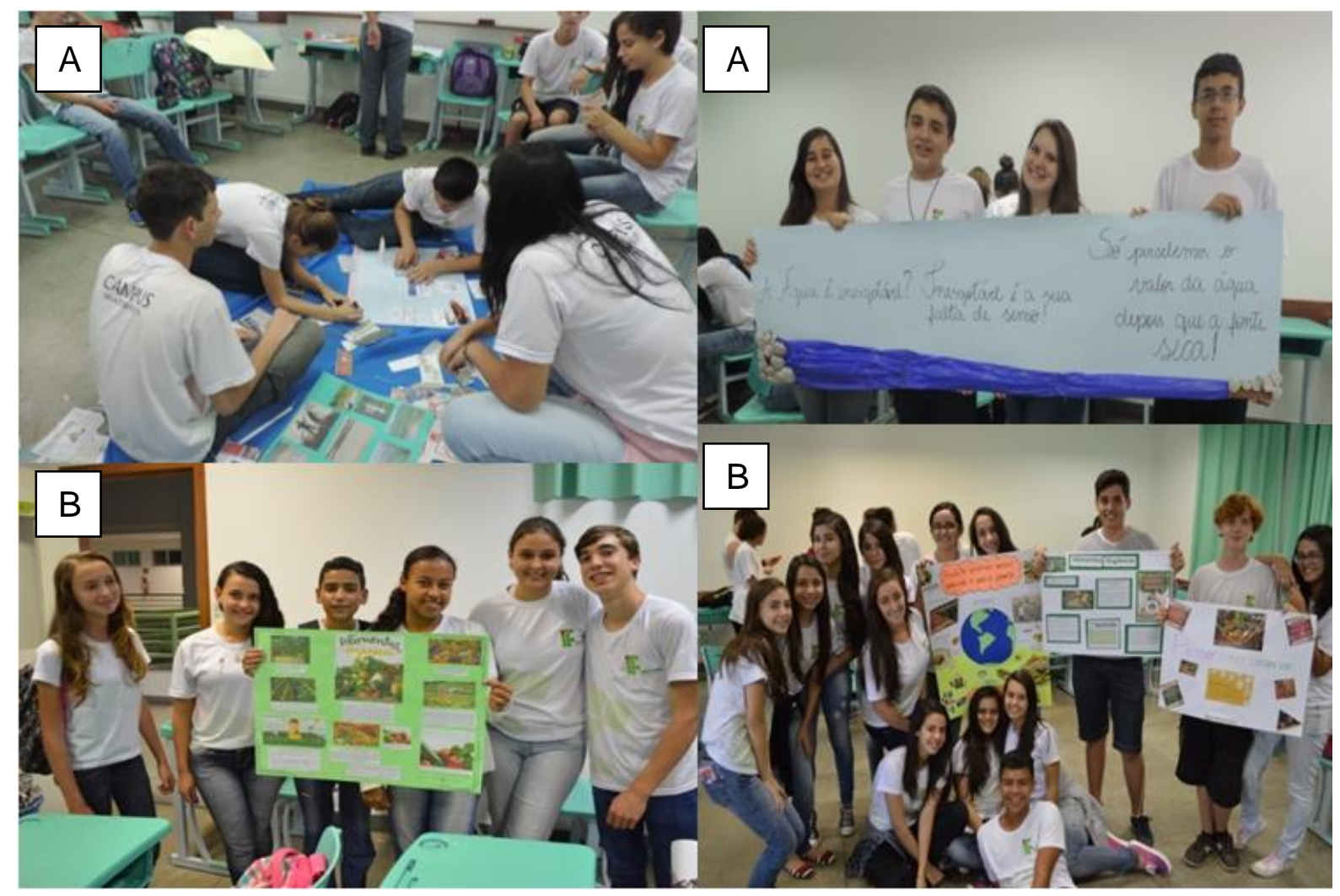

Figura 4: A - Comemoração do Dia Mundial da Água; B - Comemoração da Semana de Alimentos Orgânicos. Fonte: Elaboração dos autores.

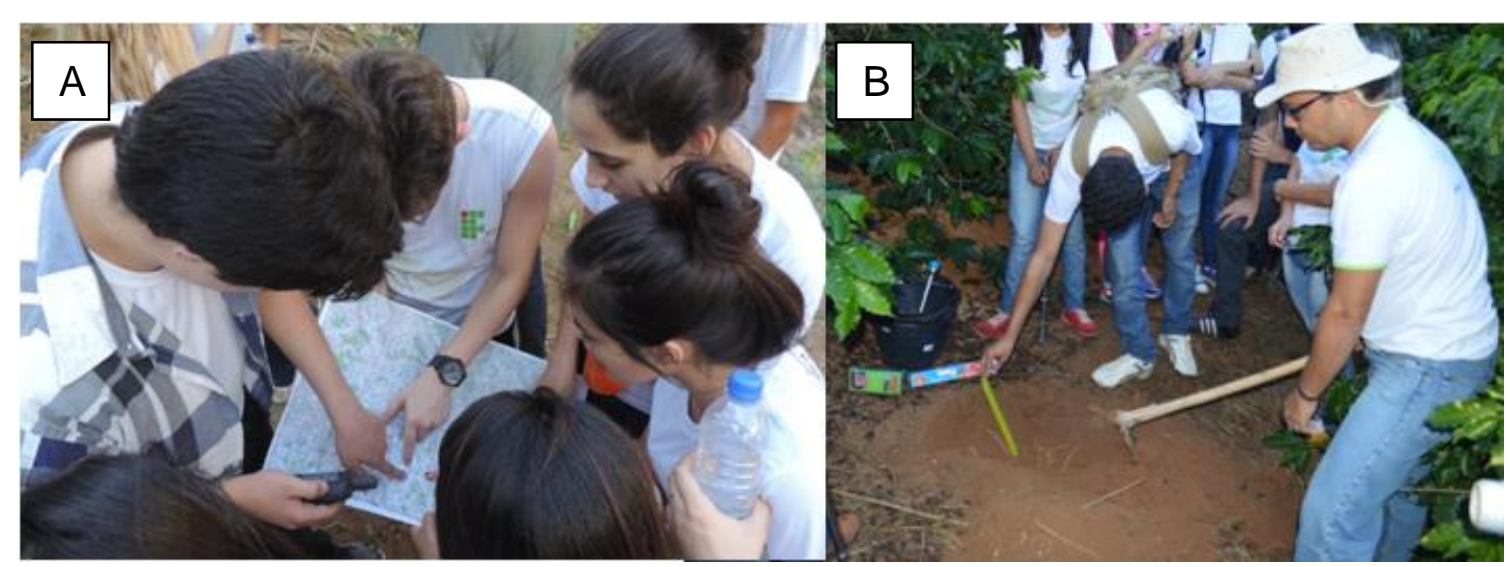

Figura 5: Diagnóstico da bacia hidrográfica do Rio Pardo $(A)$ e diagnóstico da sustentabilidade de agroecossistemas (B). Fonte: Elaboração dos autores.

A partir da análise do PPP, identificou-se uma frequência forte da macrotendência conservadora nas ações planejadas, pois estas objetivavam a promoção de seminários, palestras e mini cursos sobre a problemática ambiental, além da produção de material instrucional sobre Educação Ambiental. As metodologias centradas na transmissão de informações como aulas e palestras e apresentações de trabalhos são classificadas como práticas 
conservacionistas, por isso encontram-se no eixo vertical, uma vez que são centradas na figura de um educador que dissemina conhecimentos (TRISTÃO, 2011).

Estas práticas de disseminação de conhecimento estão enraizadas no início da história da Educação Ambiental, quando é aberto o diálogo entre a Educação e o Ambientalismo, como forma de conscientizar os indivíduos a respeito das problemáticas existentes na "Questão Ambiental", tendo a educação como instrumento de resposta à crise ambiental (MATOS, 2009).

As atividades desenvolvidas nas feiras, tanto na Feira Verde quanto na Mostra Ambiental, promoveram a apresentação de atividades das hortas verticais, divulgando conhecimentos como uso de plantas medicinais e de sementes crioulas, objetivando nortear a busca pela valorização da cultura local e regional e aspectos de melhoria na qualidade de vida. Dessa forma são classificadas como atividades verticais, ou pragmáticas, pois embora trabalhem aspectos culturais da sociedade local, não abordam a fundo as questões políticas e a complexidade das relações entre ser humano e ambiente (SILVA e CAMPINA, 2011). Portanto, é comum observar nessas ações pragmáticas a vertente da sustentabilidade voltada ao uso racional do meio ambiente (MATOS, 2009), ou seja, uma visão utilitarista dos recursos ambientais.

O pragmatismo também pode ser observado na descrição de atividades como Mostras Audiovisuais, Visitas Técnicas e Cursos de Capacitação, onde a instrumentalização e a sensibilização às problemáticas ambientais são marcadas na ação dos educadores. Normalmente ocorre nestas ações pragmáticas, o que é descrito por Loureiro e Layrargues (2001), como a ausência de clareza na discussão das políticas em Educação, não enfatizando os aspectos históricos, mas envolvendo questões técnicas e disseminando modelos de manejo que se apresentam como a solução dos conflitos.

As ações pragmáticas, como as descritas acima, caminham no sentido de fornecer alternativas ao capitalismo hegemônico, como um mecanismo de compensação da realidade, buscando, dessa forma, corrigir as imperfeições do sistema consumista (LAYRARGUES; LIMA, 2014). É possível vislumbrar esta macrotendência educacional na própria normatização, em que, por exemplo, se permite um empreendimento vultuoso, com potencial de significativo impacto ambiental, exigindo-se do empreendedor, uma contrapartida imposta por uma condicionante, como forma de compensar possíveis danos.

O pragmatismo na Educação Ambiental acaba por convergir com as concepções de consumo sustentável. Nesse sentido, Layrargues (2004) é categórico em afirmar que o desenvolvimento de atividades fim, normalmente buscam uma solução pedagógica para o problema ambiental, e pelo fato da Educação Ambiental ser um instrumento de reprodução social, pode direcionar a conservação ou a transformação social, dependendo da forma como for abordada. 
Práticas agroecológicas também marcaram o primeiro ano da SVC, disseminando ações além dos limites do município de lbatiba, estabelecendo parcerias com instituições como a Escola Família Agrícola (EFA) de Brejetuba, onde implantaram uma composteira e um minhocário, juntamente com os estudantes do curso técnico, com objetivo de produzir insumos que poderiam ser utilizados na horta da escola. Estas ações buscaram o fortalecimento da agroecologia e ressaltavam a importância da mesma no contexto da agricultura familiar e segurança alimentar.

As práticas educativas de implantação da composteira e do minhocário adquirem um cunho pedagógico colaborativo, em que todos os envolvidos participam da ação, contribuindo com seus conhecimentos e, através disto, visam alcançar um objetivo comum (CAMPOS; SANTORO; BORGES, 2003). As práticas colaborativas, onde alunos interagem com o professor, em atividades que vão além da disseminação de conhecimentos ou da busca pela sustentabilidade, trabalhando também questões sociais, são categorizadas como ação em rede ou crítica (TRISTÃO, 2011), haja vista que possibilita ao educando e à comunidade, se tornarem agentes ativos de sua história e, com isso, vislumbrar uma emancipação.

As reuniões com os agricultores familiares das comunidades trabalhadas (Figura 3), buscavam realizar um diagnóstico participativo e debater os aspectos da realidade local, rompendo com a concepção pragmática ou conservacionista em que respostas prontas são oferecidas como informação e determinados comportamentos são definidos, em primeiro momento, como prioridade a toda e qualquer comunidade (LOUREIRO, 2004b). Explicita, pois, um avanço quanto à abordagem social e cultural no trabalho da Educação Ambiental, o que equilibra a relação entre educação e ambiente, com ações que implicam na reflexão acerca das práticas sociais instauradas (LOUREIRO, 2003).

Outras ações realizadas no segundo ano (Tabela 1) foram as visitas técnicas, práticas conservadoras de Educação Ambiental (LAYRARGUES e LIMA, 2014), observando-se, pois, o cunho comportamentalista e de Alfabetização Ecológica. O autor diz ainda que, atividades de percepção ao ar livre, onde o eixo prioritário são temas ecológicos que conduzem para mudanças comportamentais, onde 0 homem é o centro das relações desenvolvidas e que abordam temas como a biodiversidade, o ecoturismo, os biomas e as experiências agroecológicas, são típicas da tendência conservacionista. $O$ trabalho de sensibilização do ser humano em relação à natureza, ressaltando aspectos da crise ambiental ocasionada pela destruição do meio ambiente, trabalhando sistemas ambientais em detrimento de questões sociais, é, complementa Santos e Toschi (2015), tipicamente caracterizado dentro dessa macrotendência conservacionista.

Ainda em análise do segundo ano de atividades da Sala Verde Caparaó, observou-se a vertente pragmática, que se baseia no pontualismo de ações como as mostras audiovisuais (Tabela 1). Este tipo de prática em 
Educação Ambiental pode ser considerado crítica, caso sejam inseridos aspectos sociais, econômicas, culturais e políticas nestas ações, mas em si, as mesmas se baseiam em ações imediatas e não procuram pela causa do problema ambiental (SANTOS; TOSCHI, 2015).

O que marca a tendência crítica, de acordo com Loureiro e Layrargues (2013) é a ruptura abrupta com padrões hegemônicos capitalistas que marcam situações em que ocorrem a reprodução social de desigualdades e os conflitos ambientais, inserindo-se, nesse viés, na própria conjectura de lutas contrahegemônicas.

Outras atividades desenvolvidas foram a apresentação de trabalhos científicos em eventos de extensão e integração, como o II Encontro de Educadores Ambientais do IFES e a I Jornada de Integração do IFES, atividades classificadas como conservacionistas.

Foi desenvolvido, na EFA, atividades e cursos com a finalidade de demonstrar as formas de manejos agroecológicos e manejos de pragas e doenças, sendo classificada com atividade pragmática no eixo horizontal. Segundo Layrargues (2004), a forma de EA hegemônica é a vertente pragmática, que busca solução para problemas socioambientais dentro dos próprios aspectos da crise.

A mostra audiovisual e o projeto de pipoca orgânica consistiram em exposições de vídeos com a temática de Educação Ambiental, ações que são pragmáticas. No projeto pipoca orgânica, os alunos, paralelo à exposição de documentários a respeito do uso de agrotóxicos, consumiram pipoca feita de milho orgânico.

O processo de categorização das práticas em Educação Ambiental, identificadas nos documentos norteadores da Sala Verde Caparaó, por meio de correntes e tendências, consiste em uma ação também proposta por vários autores, como Sorrentino (1995), Sauvé (2005), Layrargues (2004). São trabalhos baseados na inferência e análise reflexiva de materiais norteadores. Ressalta-se que essas práticas se justificam na formação de uma sociedade democrática, na inserção de dimensões políticas no trabalho educativo e na formação consciente e colaborativa do educador ambiental (SILVA; CAMPINA, 2011), condizente com o desenvolvimento de uma cidadania socioambiental.

Ao longo deste PPP é notória a preocupação com a construção de práticas baseadas no fortalecimento do desenvolvimento sustentável da região do Caparaó, por meio de uma educação afetiva pautada na sensibilização dos indivíduos, pelo apelo emocional.

Segundo Schultz et al. (2015) a construção de uma análise de PPP deve atender às necessidades de cada estudante dentro de suas especificidades, por meio de propostas de situações que possibilitem o desenvolvimento no aprendizado de cada um, buscando valorar as dimensões humanas e permitir, assim, aliado às reais necessidades locais, maior efetividade do PPP e, consequentemente, da EA.

revista brasileira educação ambiental 
E, assim como afirma Dias e Bonfim (2011), como o discurso de Educação Ambiental não é homogêneo, não existe uma Educação Ambiental adequada a qualquer contexto. No entanto, os discursos mais pontuais, voltados à promoção de reflexões em sua própria prática e na realização de atividades pontuais, baseadas em modelos pré-fabricados e que não se contextualizam com a realidade socioambiental, são características de uma tendência conservadora com a expressão de práticas tradicionais.

A promoção de curso de Introdução a Agroecologia e o plantio de mudas (Tabela 1) também se enquadram como atividades teóricas e práticas com finalidades específicas, buscando alternativas sustentáveis e disseminações de modelos acadêmicos, enquadrando-se na macrotendência conservadora.

No entanto, embora no ano 2016 tenham sido observadas práticas educativas conservadoras e pragmáticas, é perceptível a preocupação com a realização de atividades em rede, de cunho crítico e transformador do pensamento socioambiental.

Oficinas colaborativas, a realização de diagnósticos socioambientais e a elaboração de projetos estão entre atividades desenvolvidas pela Sala Verde Caparaó que aproximam a pauta ambiental com a pauta social (Tabela 1). A Educação Ambiental não pode se esquecer de associar os aspectos ecológicos aos sociais, pois esta ação garante que, verdadeiramente, seja possível intervir na realidade e se possa existir na natureza (LOUREIRO, 2007), permitindo ao homem, enxergar-se também como meio ambiente.

Não se pode considerar o ser humano como um agente de destruição por suas ações junto ao meio ambiente sem considerar que o mesmo interage de maneira diversa com o local que vive, que esta interação é inevitável e que cada um se relaciona com a natureza por meio de mediações sociais (LOUREIRO, 2007).

$\mathrm{Na}$ Educação Ambiental Crítica não existe verdade absoluta, conceitos sem história, e educação separada da sociedade. Seria difícil não notar, por meio dessa análise reflexiva, a inclinação das práticas educativas ambientais desenvolvidas pela Sala Verde Caparaó à tendência Crítica, com desenvolvimento de atividades em rede ao longo do terceiro ano de funcionamento.

Essa propensão pode estar relacionada à atualização do Projeto Político Pedagógico, documento norteador da práxis educativa da Sala Verde Caparaó, o qual demonstrou preocupações com o desenvolvimento de práticas vinculadas a aspectos sociais, político e cooperativos.

Desde o final do terceiro ano do projeto SVC notou-se a tendência à realização de práticas educativas preocupadas com os aspectos socioambientais que compunham as relações presentes na região do Caparaó, refletindo-se em atividades de diagnósticos participativos com comunidades 
rurais existentes ao redor do município de lbatiba. A mudança nesta percepção da equipe da Sala Verde Caparaó resultou na atualização documental do PPP.

A atualização do PPP da Sala Verde Caparaó ocorreu no ano de 2017, término do ciclo das atividades relatadas, e o novo documento demonstrou maior preocupação com a abordagem da política em Educação Ambiental, trazendo, à luz, tendências histórico crítica.

A atualização contínua do Projeto Político Pedagógico de um espaço educativo pode potencializar o desenvolvimento de práticas reflexivas, buscado contribuir, de forma efetiva, para uma investigação eficiente e eficaz das possíveis causas e efeitos da problemática ambiental que atormentam a sociedade nos dias atuais (GRZEBIELUKA; SILVA, 2015).

A análise do PPP da Sala Verde Caparaó sob a ótica da Educação Ambiental Crítica permite que a comunidade se integre numa perspectiva educativa no desenvolvimento de projetos e no levantamento e apontamento da possibilidade de resolução dos problemas socioambientais (SILVA; CARNIATTO; POLINARSKI, 2009).

\section{Conclusões}

A partir da análise dos documentos norteadores da Sala Verde Caparaó, identificou-se uma variedade de ações educativas em Educação Ambiental, desenvolvidas em diferentes setores da sociedade, como escolas e comunidades rurais, que vão desde a realização de palestras ao desenvolvimento de mostras audiovisuais, visitas técnicas e avaliação da sustentabilidade de agroecossistemas.

Quando se refere à natureza das práticas pedagógicas, constatou-se que as ações desenvolvidas puderam ser enquadradas dentro das três macrotendências pedagógicas, constituindo um trabalho heterogêneo, construído ao longo desses anos. No entanto, a maioria das práticas desenvolvidas foi categorizada dentro dos ideais pragmáticos, uma vez que buscavam obter, por meio da Educação Ambiental, um meio para se alcançar a sustentabilidade, inseridos no viés gerencial.

A gradativa mudança na abordagem das práticas educativas, inicialmente pautadas em ações conservadoras e pragmáticas, para uma abordagem mais crítica, revelou uma mudança de atitudes ao relacionar os aspectos sociais, políticos e históricos no desenvolvimento das práticas de Educação Ambiental promovidas pela SVC, conduzindo a uma reformulação do PPP.

A relação entre as ações desenvolvidas pela Sala Verde Caparaó e as macrotendências em Educação Ambiental é reflexo da estrutura prática do seu Projeto Político Pedagógico, que interliga a natureza das ações com seu propósito fundamental. 
Agradecimentos: Ao Instituto Federal do Espírito Santo - campus Ibatiba. Ao Ministério do Meio Ambiente.

\section{Referências}

ALMEIDA, V. S. Estágio supervisionado com enfoque na Educação Ambiental: perspectivas de uma sala verde. 2018. 74 f. Dissertação (Mestrado em Educação Agrícola) - Universidade Federal Rural do Rio de Janeiro, Seropédica - Rio de Janeiro. Disponível em: <https://tede.ufrri.br/handle/jspui/2786>. Acesso em: 20 de mai de 2019.

BOURDIEU, P. O poder simbólico. 11. ed. Rio de Janeiro: Bertrand Brasil, 2007. $313 \mathrm{f}$.

CAMPOS, F. C. A.; SANTORO, FI. M.; BORGES, M. R. S. Cooperação e aprendizagem on-line. Rio de Janeiro: DP\&A, 2003.

CUBA, M. A. Educação Ambiental nas escolas. Educação, Cultura e Comunicação, v. 1, n. 2, p. 23-31, 2010.

DENARDIN, V. F.; SULZBACH, M. T. Os possíveis caminhos da sustentabilidade para a agropecuária da região Oeste de Santa Catarina. Desenvolvimento em Questão, v. 3, n. 6, p. 87-115, 2005.

DIAS, B. C.; BOMFIM, A. M. A "teoria do fazer" em Educação Ambiental Crítica: uma reflexão construída em contraposição à Educação Ambiental Conservadora. Anais do VIII Encontro Nacional De Pesquisa Em Educação Em Ciências, v. 8, 2011.

FONTAN, I. C. I.; CARVALHO, A. H. O.; GUIMARÃES, E. C. S. Relatos de experiência: a Sala Verde Caparaó e a Educação Ambiental não formal. UNIFESO-Humanas e Sociais, v. 3, n. 03, 2016.

GADOTTI, M. A questão da educação formal/não-formal. Sion: Institut Internacional des Droits de 10 Enfant, p. 1-11, 2005.

GRZEBIELUKA, D.; SILVA, J. A. Educação Ambiental Na Escola: do Projeto Político Pedagógico a prática docente. Revista Monografias Ambientais, v. 14, n. 3, p. 76-101, 2015.

GUIMARÃES, M. Educação Ambiental crítica. Identidades da Educação Ambiental brasileira. Brasília: Ministério do Meio Ambiente, p. 25-34, 2004.

HERNÁNDEZ, F.; VENTURA, M. A organização do currículo por projetos de trabalho: $O$ conhecimento é um caleidoscópio. 5 Ed. Porto Alegre: Artes Médicas, 1998.

JACOBI, P. R. Educação Ambiental: o desafio da construção de um pensamento crítico, complexo e reflexivo. Educação e pesquisa, v. 31, n. 2, p. 233-250, 2005. 
LAYRARGUES, P. P. Identidades da educação brasileira. Ministério do Meio Ambiente/Diretoria de Educação Ambiental, 2004.

LAYRARGUES, P. P.; LIMA, G. F. C. Mapeando as macro-tendências políticopedagógicas da Educação Ambiental contemporânea no Brasil. In: Encontro Pesquisa em Educação Ambiental, 1, 2011, Rio Claro. Anais do I EACB: Pesquisa em Educação Ambiental. Rio Claro: p. 1-15, 2011.

LAYRARGUES, P. P.; LIMA, G. F. C. As macrotendências político-pedagógicas da Educação Ambiental Brasileira. Ambiente \& Sociedade, v. 17, n. 1, p. 2340, 2014.

LIMA, G. F. C. Educação Ambiental: formação, identidades e desafios. 1. ed. Campinas: Papirus, 2011.

LIMA, D. S. A construção da gestão democrática sob a perspectiva do Projeto Político Pedagógico. Trabalho de Conclusão de Curso (Graduação em Pedagogia) - Universidade Federal do Rio Grande do Norte, Natal, 2017, 27 f.

LOUREIRO, C. F. B. Premissas teóricas para uma Educação Ambiental transformadora. Ambiente \& Educação, v. 8, n. 1, p. 37- 54, 2003.

LOUREIRO, C. F. B. Educação Ambiental transformadora. Identidades da Educação Ambiental brasileira. Brasília: MMA, p. 65-84, 2004a.

LOUREIRO, C. F. B. Educar, participar e transformar em Educação Ambiental. Revista Brasileira de Educação Ambiental, v. 0, n. 0, p. 13-20, 2004b.

LOUREIRO, C. F. B. Educação Ambiental crítica: contribuições e desafios. Conceitos e práticas em Educação Ambiental na escola, p. 65, 2007.

LOUREIRO, C. F. B. Contra-Hegemônica. Trabalho, educação e saúde, v. 11, n. 1, p. 53-71, 2013.

LOUREIRO, C. F. B.; LAYRARGUES, P. P. Educação Ambiental Nos Anos 90. Mudou, Mas Nem Tanto. Brasília: Revista Brasileira de Meio Ambiente, v. 9, n. 5, p. 6-7.2001, 2001.

LUZ, L. Projeto Político Pedagógico de Educação Ambiental e Agricultura Familiar da Floresta Nacional de Tefé. MMA/ICMBio. Disponível em: $<$ http://www.icmbio.gov.br/educacaoambiental/images/stories/biblioteca/PPPea/ PPPEA - FLONA Tef\%C3\%A9.pdf>. Acesso em 24 de mai de 2019.

MATOS, M. A. E. A metodologia de projetos, a aprendizagem significativa e a Educação Ambiental na escola. Ensino, Saúde e Ambiente Backup, v.2 n.1, p 22-29, 2009.

MEDEL, C. R. M. A. Projeto Politico Pedagogico: Construção e Implementação na Escola. 2. Ed. Campinas: Autores Associados, 2008.

MIRANDA, E. C. S. S.; OCHOSKI, M.; NETO, B. P.; ALMEIDA, V. S.; SOARES, A. M. D. Agrofloresta pedagógica: cultivando a agroecologia no espaço escolar. Cadernos de Agroecologia, v. 13, n. 1, 2018. 
MIOTTO, H. S.; GONÇALVES, R. C.; DINARDI, A. J. A Inserção da Educação Ambiental nos Documentos que Norteiam os Diferentes Níveis de Formação. Rio Grande do Sul: REMEA-Revista Eletrônica do Mestrado em Educação Ambiental, n. 1, p. 295-307, 2018.

RIBEIRO, E. S.; SILVA, B. E. Revisão e modificações em um PPP sob as perspectivas da gestão democrática voltada à educação Infantil. Revista Científica Doctum: Educação, v. 1, n. 1, 2015.

SANTOS, J. A.; TOSCHI, M. S. Vertentes da Educação Ambiental: da conservacionista à critica. Fronteiras: Journal Of Social, Technological And Environmental Science, v. 4, n. 2, p. 241-250, 2015.

SAUVÉ, L. Uma Cartografia Das Correntes Em Educação Ambiental. Educação Ambiental: pesquisa e desafios, p. 17-44, 2005.

SILVA, F. D. da. Projeto político pedagógico aplicado a centros de Educação Ambiental e a salas verdes: manual de Orientação. Brasília: Ministério do Meio Ambiente/Diretoria de Educação Ambiental. 2005.

SILVA, M. D. da; CARNIATTO, I.; POLINARSKI, C. A. Projeto políticopedagógico como instrumento para Educação Ambiental formal. Anais do VII Enpec - Encontro Nacional de Pesquisas em Educação em Ciências, Florianópolis, 2009.

SILVA, R. L. F.; CAMPINA, N. N. Concepções de Educação Ambiental na mídia e em práticas escolares: contribuições de uma tipologia. Pesquisa em Educação Ambiental, v. 6, n. 1, p. 29-46, 2011.

SCHULTZ, D.; SILVA, J.; MARIA, J. T.; HALILA, N. F. K.; HAURESKO, C. O Projeto Político Pedagógico na escola: análise dos PPP do Colégio Estadual Padre Chagas e Colégio Estadual do Campo da Palmeirinha, Pelo PIBIDGeografia. In: 2015, Paraná. Anais do IV Fórum das Licenciaturas/VI Encontro do PIBID/II Encontro PRODOCÊNCIA: Diálogos entre licenciaturas: demandas da contemporaneidade. Paraná, 2015.

SORRENTINO, M. Educação Ambiental e universidade: um estudo de caso. Tese (Doutorado em Educação). São Paulo: Universidade de São Paulo, 1995.

SOUSA, T.; SANT'ANA JÚNIOR, H. A. de. Educação Ambiental crítica ou conservadora? Elementos para uma reflexão crítica acerca do projeto ECOA. Ambiente \& Educação, v. 23, n. 1, 2018.

TRISTÃO, V. T. V. Educação Ambiental não formal: a experiência das organizações do terceiro setor. 2011. Tese (Doutorado em Educação) Universidade de São Paulo, São Paulo, 2011.

VEIGA, I. P. A. Inovações e projeto político-pedagógico: uma relação regulatória ou emancipatória? Cadernos Cedes, v. 23, n. 61, p. 267-281, 2003.

VEIGA, I. P. A. Perspectivas para reflexão em torno do projeto políticopedagógico. In: Projeto político-pedagógico da escola: uma construção possível. 13 ed. Campinas, SP: Papirus. p.09-32, 2008. 